Portland State University

PDXScholar

\title{
Measuring the Accuracy of Predictions from Patient- Specific Models of Intracranial Pressure Dynamics
}

Wayne W. Wakeland

Portland State University, wakeland@pdx.edu

Follow this and additional works at: https://pdxscholar.library.pdx.edu/sysc_fac

Part of the Biomedical Commons

Let us know how access to this document benefits you.

\section{Citation Details}

Wakeland, W. Measuring the Accuracy of Predictions from Patient-Specific Models of Intracranial Pressure Dynamics. Poster presentation at the 6th International Conference on Complexity in Acute Illness (ICCAI), 2007 in Long Beach, CA.

This Poster is brought to you for free and open access. It has been accepted for inclusion in Systems Science Faculty Publications and Presentations by an authorized administrator of PDXScholar. Please contact us if we can make this document more accessible: pdxscholar@pdx.edu. 


\section{Measuring the Accuracy of Predictions from Patient-Specific Models of Portland State Intracranial Pressure Dynamics \\ Wayne Wakeland \\ Objective}

Determine the prediction capability of a computer model of ICP dynamics

Background

- Outcomes for elevated ICP following traumatic brain injury (TBI) remain mixed

- TBI remains leading cause of death and disability in children

- Sophisticated computer models calibrated to fit patientspecific clinical data - No studies have reported the prediction capability of these models

\section{Discussion/Conclusion}

- Despite small error in model fit to data, model prediction error is too large to be clinically useful

- Caution warranted: prediction is hard!! $\rightarrow$ A good fit between model and historical data may not yield good predictions!
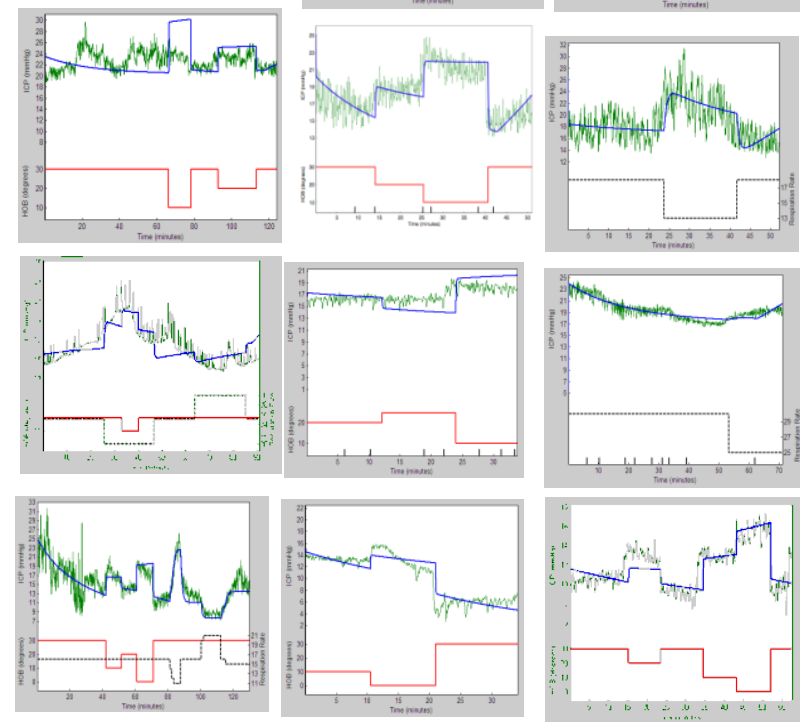
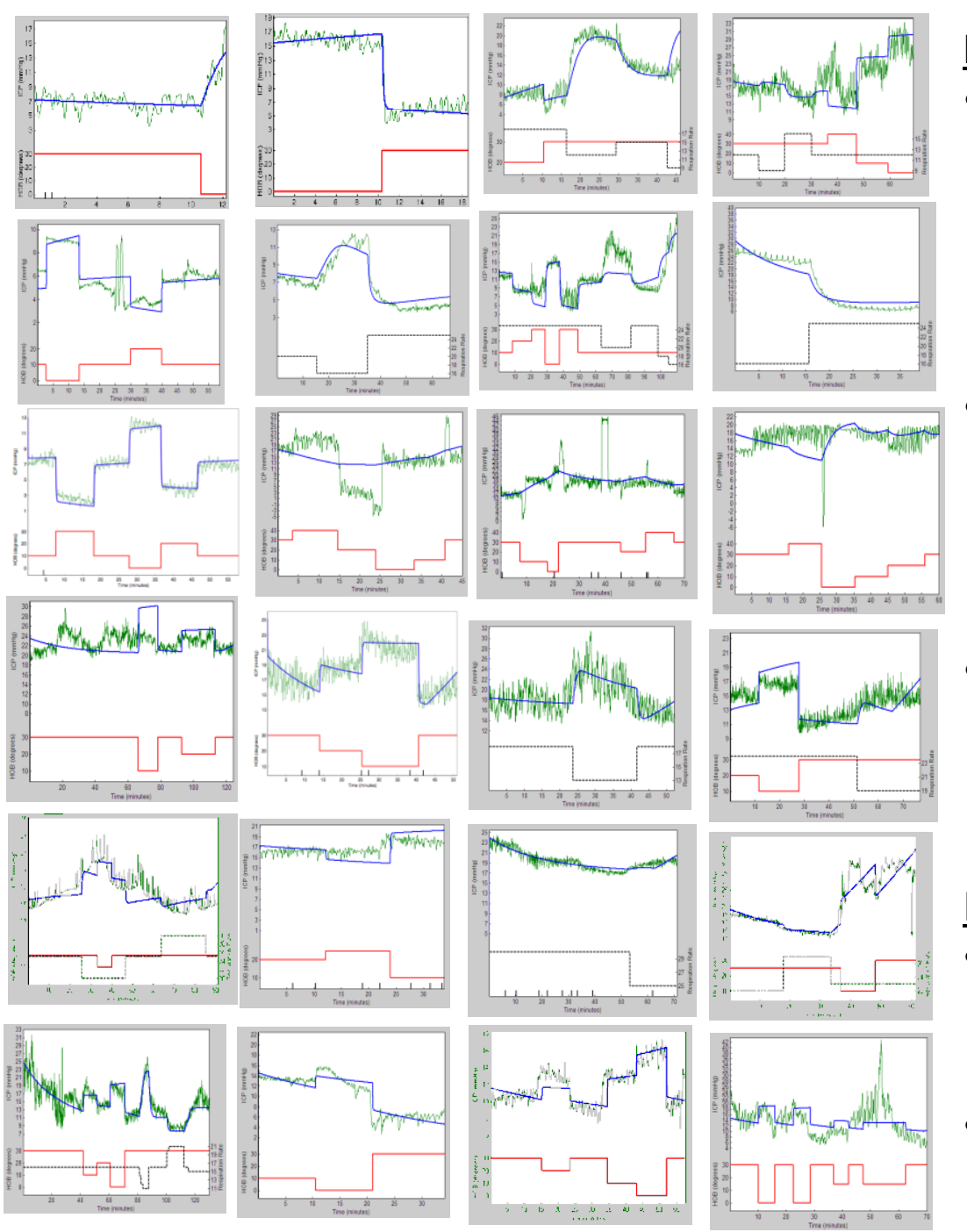

Figure 1: Model ICP (blue) vs. Actual ICP (green), w/HOB (red) and Respiration Rate (dotted black)

ICCAI 2007
Long Beach, CA
Methods

- Clinically annotated prospective data collected: mild physiologic challenge protocol

-- Head of bed: 0 to 30 degrees

-- Respiration Rate: mild hyper- to hypoventilation

-- 9 TBI patients, 24 sessions

- Data from early in single long session or from prior sessions used to estimate patient-specific parameter values for computer model of ICP dynamics

-- Curve-fitting optimization minimized squared error, modeled ICP vs. data

- Resulting patient-specific models used to predict patient's ICP response to

-- Later in the same session

-- In subsequent sessions

$\underline{\text { Results }}$

- Avg. mean absolute error (MAE) for fitness of model to the data: $1.9 \mathrm{mmHg}$

$\rightarrow$ for segments with avg. mean absolute deviation of $3.1 \mathrm{mmHg}$

- Avg. MAE for predictions:

$4.0 \mathrm{mmHg}$ w/in same session;

$6.7 \mathrm{mmHg}$ across sessions interventions 